\title{
Falar cafajeste. De Manuel Bandeira a Dalton TREVISAN VIA Joaguim Pedro de Andrade Speaking slang. From Manuel Bandeira to Dalton Trevisan via Joaquim Pedro de Andrade
}

Ainda existem mulheres bastante puras para fazer vontade aos viciados

M. Bandeira

- Quer que morda ou beije?

- Sim, doutor! Sim, doutor!

D. Trevisan

Jorge Wolff*

\begin{abstract}
RESUMO
A partir da sugestão do "falar cafajeste" de Manuel Bandeira em Itinerário de Pasárgada (1954), o texto articula a visão do chulo-grotesco no poeta da Estrela da vida inteira com aquela do contista das Novelas nada exemplares, Dalton Trevisan. A articulação é proposta a partir das relações de ambos os escritores com o cinema e, especificamente, com o cineasta Joaquim Pedro Andrade, que estreou em 1959 com o poeta do Castelo, curta-metragem dedicado a Bandeira, e que, no início dos anos setenta, compartilhou com Trevisan a realização de Guerra conjugal, longa-metragem de 1975.
\end{abstract}

Palavras-chave: Manuel Bandeira; Dalton Trevisan; Joaquim Pedro de Andrade.

Universidade Federal de Santa Catarina. 


\begin{abstract}
From the suggestion of the "coarse speaking" by Manuel Bandeira in Itinerário de Pasárgada (1954), this text articulates the vulgar-grotesque view of the poet of Estrela da vida inteira with that by Dalton Trevisan, the short story writer of Novelas nada exemplares. The articulation is proposed from the relations of both with cinema, and specifically with the filmmaker Joaquim Pedro de Andrade, who first appeared in the screen, in 1959 with the film 0 poeta do castelo, a short length film dedicated to Manuel Bandeira, and who in the beginning of the 1970s created together with Trevisan the feature film Guerra Conjugal (1975).
\end{abstract}

Key-words: Manuel Bandeira; Dalton Trevisan; Joaquim Pedro de Andrade.

Foi Berta Waldman, a grande leitora de Dalton Trevisan, Clarice Lispector e Nelson Rodrigues, quem lembrou a vontade de "falar cafajeste" manifestada por Manuel Bandeira em seu Itinerário de Pasárgada. A autobiografia poético-existencial de Bandeira, de $1954^{1}$, é reveladora não apenas de sua poesia e de sua trajetória intelectual pública e privada, mas serve igualmente para iluminar o retrato cinebiográfico feito pelo jovem Joaquim Pedro de Andrade, O poeta do Castelo, de $1959^{2}$. Nele ouve-se o poeta nascido em Pernambuco recitando trechos de seus conhecidos "Belo Belo" e "Vou-me embora pra Pasárgada", sendo este o poema central do livro intitulado significativamente Libertinagem, de 1930. No final do famoso poema, o tão contido "Manú" (como o chamava Mário de Andrade) fala o "cafajeste elegante", valha a contradição que, no entanto, soava ofensivo e escandaloso durante as primeiras décadas do século XX, em meio à vaga de modernização conservadora vivida no país. Mais tarde, logo após a morte de Manuel Bandeira, em 1968, Joaquim Pedro de Andrade e Dalton Trevisan uniriam forças para levar a cabo um projeto cinematográfico não menos "ofensivo e escandaloso", no momento de maior repressão imposta pela ditadura militar no Brasil. Finalizado em 1975 e imediatamente censurado pelo governo, Guerra conjugal é uma inspirada costura feita pelo cineasta carioca a partir de dezesseis contos de Trevisan, com diálogos assinados pelo próprio escritor.

1 Incluída em BANDEIRA, M. (1986). Também é possível encontrar o texto de Bandeira na internet em < http://www.scribd.com/doc/5564060/Manuel-Bandeira-Itinerario-de-Pasargada $>$.

2 O poeta do castelo encontra-se disponível em: <http://www.youtube.com/watch? $\mathrm{v}=\mathrm{XjlsWMCq1qM}>$. 
Em um breve artigo intitulado "A medida do cafajeste" e escrito para a coletânea Os pobres na literatura brasileira, organizada pelo crítico Roberto Schwarz, Berta Waldman apresenta logo nas primeiras linhas uma, à primeira vista improvável ou mesmo incongruente proposta de linhagem Bandeira-Trevisan, posto que o primeiro é conhecido como o fino analista das coisas mais cotidianas e o segundo como o fino analista da mais completa abjeção. No entanto, diz ela:

Já Manuel Bandeira, em Itinerário de Pasárgada, manifestava sua vontade de "falar cafajeste". Como ele, outros poetas e prosadores foram certamente tocados pela mesma vontade. Se se pretender perfilar a linhagem dessa figura, será preciso levantar onde e de que modo aparece a nota cafajeste em nossa literatura. De qualquer modo, nela certamente se enquadrariam, como verdadeiros paradigmas, alguns personagens de Dalton Trevisan (WALDMAN apud SCHWARZ, 1983, p. 201).

Já, como epígrafe do último capítulo de seu ensaio Do vampiro ao cafajeste. Uma leitura da obra de Dalton Trevisan, Waldman havia resgatado e destacado essa passagem do Itinerário de Pasárgada: “... dessa vez queria brincar mesmo falando cafajeste", diz a voz de Bandeira na abertura do derradeiro capítulo do ensaio, concluído justamente com a inclusão do "Vampiro de Curitiba" - a alcunha de Trevisan desde o aparecimento do livro homônimo de 1965 - na antiga tradição universal dos pícaros, malandros e cafajestes, vistos estes últimos como "antimalandros", ou seja, um tipo de malandro esvaziado de qualquer conotação folclórica (cf. WALDMAN, 1982, p. 121-128). A partir disso, seria então necessário perguntar o que, precisamente, caberia a Manuel Bandeira nessa proposta, algo que a ensaísta, salvo engano, não chegou a desenvolver. Onde e como a "nota cafajeste", a nota "suja" ou "grotesca" se desdobram em sua poética - condensada no Itinerário de Pasárgada - é o que se pretende assinalar neste trabalho, seguido de suas extensões ao âmbito do cinema através da figura de Joaquim Pedro para, finalmente, chegar ao universo de Dalton Trevisan na companhia do mesmo cineasta.

Como se sabe, a "nota cafajeste" igualmente atravessa de maneira explícita a filmografia de Joaquim Pedro de Andrade desde o curta-metragem Couro de gato (realizado em 1960 e incluído em Cinco vezes favela, 1962), passando por Garrincha, alegria do povo (1963), para culminar, na década de sessenta, com a sua versão "grotesca" de Macunaíma, de 1969. Mas, apesar das dificuldades por que passou o cinema brasileiro durante a década 
seguinte, muita água havia ainda para rolar no campo de seu namoro crítico com a pornochanchada, em Guerra conjugal e Vereda tropical (parte de Contos eróticos, 1977), e com a literatura brasileira, de que $O$ homem do pau-brasil (1981), baseado em diversos textos de Oswald de Andrade, acabaria sendo o exuberante réquiem.

Antes, porém, da realização de todos esses filmes, ou seja, antes do Cinema Novo, de que foi um dos grandes artífices -, sua estreia "profissional" se deu com o poeta do Castelo, realizado apenas cinco anos depois do aparecimento do Itinerário de Pasárgada. o que leva à seguinte sugestão, que o cineasta provavelmente assinaria embaixo, tendo trabalhado em colaboração, conforme mencionado acima, com o próprio autor de $A$ guerra conjugal (caso excepcional, aliás, na larga trajetória de escritor recluso de Dalton Trevisan): o "vampiro curitibano" igualmente engendrou sua Pasárgada, mas uma Pasárgada infernal, impiedosa, sem concessões e, assim, como é de seu estilo, pôs tudo a perder, uma vez que o "rebaixamento" através do "bagaço de linguagens desgastadas" sintetizam a "medida do cafajeste", nos termos de Berta Waldman (1983, p. 203). Segundo a hipótese de Do vampiro ao cafajeste, resumida no artigo recém citado, esses detritos de linguagem são pastiches das formas de enunciação dos mais populares meios de comunicação de massa, como a radionovela e a fotonovela, no momento de sua emergência.

Em O poeta do Castelo, filme realizado precisamente nesse momento desenvolvimentista da sociedade brasileira, vê-se o poeta, tradutor e belo ator Manuel Bandeira - conforme o comprova o filme - no mais trivial de seu dia a dia, desde a hora do café da manhã em seu pequeno e moderno apartamento no centro do Rio, com as novidades características do imediato pós-guerra, da torradeira elétrica ao telefone e a pesada máquina de escrever posta sobre uma mesinha móvel com a qual consegue trabalhar na cama. o filme é "mudo", mas, além da trilha sonora com música clássica nacional, superpõe-se a voz do poeta recitando, como foi dito acima, "Belo Belo" e "Vou me embora para Pasárgada", que diz em seus últimos versos, "desenvolvimentistas" avant la lettre:

Em Pasárgada tem tudo

É outra civilização

Tem um processo seguro

De impedir a concepção

Tem telefone automático

Tem alcalóide à vontade

Tem prostitutas bonitas

Para a gente namorar

(BANDEIRA, 1993, p. 144) 
O apartamento de Bandeira na região do Castelo, no centro do Rio, apresenta boa parte desta "outra civilização", conforme a dissecação de um espaço privado da grande urbe moderna levada a cabo no filme, à exceção, talvez, dos alcalóides e das prostitutas. Algo que vai tomar todos os lugares e situações sob a forma das sintéticas sátiras de Dalton Trevisan a partir, precisamente, do imediato pós-guerra, os anos 1940 e 50. A propósito da abjeção e do grotesco, caberia enfatizar a opção pela sujeira das ruas vista em $O$ poeta do castelo, opção esta feita expressamente pelo cineasta, que, no texto "O poeta filmado", publicado no Diário de Notícias de 17 de abril de 1965, informaria que fez o serviço de limpeza urbana do local atrasar várias horas a fim de concluir as filmagens conforme lhe convinha. O poeta atravessa uma calçada extremamente suja ${ }^{3}$, cujos restos podem ser tomados como metáfora da morte - presença frequente nos poemas de Bandeira -, como também poderiam ser tomados como metáfora da vida, já que o "feio" e o "sujo" transmutados em poética foram atribuídos a Bandeira, como se viu, sob a forma do desejo de "falar cafajeste", o que Dalton Trevisan levaria ao limite posteriormente (e segue fazendo em sua oitava década de vida).

\section{TRADUÇõES MALANDRAS}

Quando Bandeira discorre, no Itinerário de Pasárgada, sobre a atividade de "traduzir para o moderno" - o que fez na coluna "Mês Modernista" do jornal $A$ Noite nos idos de 1925 -, menciona duas "traduções" do português português para o português brasileiro, a partir de textos de dois clássicos da língua de Luís de Camões, Bocage e Joaquim Manoel de Macedo, o popular romancista brasileiro do século XIX. Em sua "tradução", quer dizer, brincadeira em forma de recriação em versos livres do romance A Moreninha (1844), é possível sentir na figura de Teresa a presença antecipada de Maria, a eterna mulher traída dos mil Joões de Dalton Trevisan ${ }^{4}$. Dizia Bandeira, abusando dos clichês românticos contra eles próprios (como o faz, à sua maneira, Trevisan):

Mulher, irmã, escuta-me: não ames,

Quando a teus pés um homem terno e curvo

3 Vale lembrar que, em "Carta-poema”, Manuel Bandeira escreve ao prefeito, exigindo a urbanização da área central do Rio, chamada Castelo, onde morava (daí o título do filme. Cf. BANDEIRA, 1993, p. 313-314).

Tendo a "repetição diferencial" como marca registrada, o obsessivo contista, a partir dos anos setenta, passa a narrar situações cujos protagonistas são invariavelmente chamados de João e Maria (cf. WALDMAN, 1978 e 2007). 
Jurar amor, chorar pranto de sangue, Não creias, não, mulher: ele te engana! As lágrimas são galas da mentira E o juramento manto de perfídia. (BANDEIRA, 1986, p. 77)

Prossegue então o poeta, com o que chegamos à citação destacada por Berta Waldman: "Bem, dessa vez eu queria mesmo brincar falando cafajeste, e a coisa foi apresentada como "tradução pracaçanje" (sendo "caçanje" o português incorreto atribuído ao grupo étnico angolano homônimo):

Teresa, se algum sujeito bancar o sentimental em cima de você E te jurar uma paixão do tamanho de um bonde

Se ele chorar

Se ele se ajoelhar

Se ele se rasgar todo

Não acredita não Teresa

É lágrima de cinema

É tapeação

Mentira

CAI FORA.

(BANDEIRA, 1986, p. 78)

De fato, o poema resultante de sua "tradução" de uma língua para a mesma-outra língua poderia ser lido como um haicai à maneira daltoniana, um microconto ou "ministória" satírica que, por vezes, lhe ocorre inclusive em versos. Bandeira, a propósito de seu poema "Balada das Três Mulheres do Sabonete Araxá" (BANDEIRA, 1993, p. 150), no mesmo Itinerário, faz referências às marcas da "seriedade da atitude" e o "gosto do decoro verbal" da chamada "geração de 45", às quais se contrapõe claramente: "Eis um poema que à geração de 45 deve parecer bem cafajeste. [...] A mim sempre me agradou, ao lado da poesia de vocabulário gongorinamente seleto, a que se encontra não raro na linguagem coloquial e até na do baixo calão" (BANDEIRA, 1986, p. 82). Aqui encontramos e entroncamos em definitivo com a linguagem ferina de Trevisan, conduzida ao inferno provinciano de outra cidade grande. Porém, antes, vale recordar a pudicícia do próprio poeta pernambucano-carioca, quem confessa inclusive ter sido forçado ou convencido por Mário de Andrade a participar da página modernista de $A$ Noite, em arranjo atribuído a Oswald de Andrade ${ }^{5}$. Para incluir um único verso longo,

5 Como é bem conhecido, Manuel Bandeira "converteu-se" ao vanguardismo brasileiro do início do século XX, embora evitasse as polêmicas e a exposição a todo custo, o que o fez também recusar o convite para participar pessoalmente da Semana de Arte Moderna de 1922. 
e visto como obsceno, no poema "Infância", ele chega a pedir a bênção de um padre. Diz o longo e divertido verso, incluído em Belo Belo, reunião de poemas dos anos 30: "Uma noite a menina me tirou da roda de coelho-sai, me levou, imperiosa e ofegante, para um desvão da casa de Dona Aninha Viegas, levantou a sainha e disse mete" (BANDEIRA, 1993, p. 209) - o que, de novo, poderia ser tomado como uma ministória à Trevisan. No Itinerário de Pasárgada, em versão calculada, o poeta busca explicar o que temia em relação à leitura desse verso, com o qual revela contar com um universo de leitores dos oito aos oitenta anos:

o que eu temia não era a condenação dos homens graves, nem da crítica desafeta, que me atribuísse intenção de escândalo. Não, o que eu não queria era chocar as minhas fãs menores de dezesseis anos. Afinal o meu escrúpulo foi-se gastando com o tempo, é verdade que ajudado pela opinião de amigos, alguns deles católicos e um até sacerdote, que me tranqüilizou dizendo: "Muito inocente, muito inocente" (BANDEIRA, 1986, p. 95).

Quanto a Dalton Trevisan, sua "apropriação de Pásargada" - esse território mítico da libertinagem - não utiliza apenas um "vocabulário gongorinamente seleto", como igualmente se inscreve na tradição da viagem dantesca, além de pantagruélica, através de "novelas nada exemplares", conforme o título de seu primeiro livro, aparecido justamente em 1959. O mergulho de Joaquim Pedro na gozosa e grotesca fonte literária de Trevisan é antecedido, portanto, pela figura de Bandeira, de quem era amigo e afilhado. Seu pai, o escritor Rodrigo Melo Franco de Andrade, idealizador e primeiro presidente do Instituto Nacional de Patrimônio Histórico e Artístico sob Getúlio Vargas, era amigo íntimo do poeta do Castelo, conforme também se pode ler no Itinerário:

Se tudo o que possuo me veio da poesia, não sei de recompensa que ela me tenha dado maior do que o afeto inalterável em tantos anos desse homem, a quem tantos amigos devem tantos serviços e nenhum aborrecimento. Minha irmã e Rodrigo foram as duas pessoas que conheci mais dotadas do gênio da amizade (BANDEIRA, 1986, p. 86).

Tal ligação é altamente esclarecedora a respeito de tudo o que se desvela no primeiro filme de Joaquim Pedro, diante de quem - além da equipe de filmagem, seus fios e refletores - Bandeira resolve fixar em imagens-em-movimento o seu cotidiano e apresentar ao grande público a sua vocação 
de ator, sempre enfatizada pelo cineasta em depoimentos sobre o filme. E, de modo bastante significativo, esta faceta do poeta já estava presente no Itinerário de Pasárgada:

Sim, gosto de ser musicado, gosto de ser traduzido e... de ser fotografado. Criancice? Deus me conserve as minhas criancices! Talvez neste gosto, como nos outros dois, o que há seja o desejo de me conhecer melhor, sair fora de mim para me olhar como puro objeto (BANDEIRA, 1986, p. 74).

É possível entender, a partir daí, a satisfação de Manuel Bandeira ao se ver no filme, como o fez, elogiando a iniciativa do Instituto Nacional do Livro da era Juscelino Kubitschek, patrocinador da produção, nas páginas do Jornal do Brasil no dia 15 de novembro de 1959. E, por contraste, também é possível entender a insatisfação de Gilberto Freyre com o jovem diretor e, ainda que não o diga, consigo próprio pela "má atuação" no filme dedicado ao autor de Casa Grande e Senzala, O mestre de Apipucos, realizado e lançado junto com $O$ poeta do castelo (e depois separados por decisão do cineasta). Freyre o manifestaria com todas as letras em artigo para a revista O Cruzeiro, de grande circulação à época, do dia de 12 de março de 1960. Nele reclama, sobretudo, da montagem feita por Joaquim Pedro, que teria privilegiado antes a casa-grande aristocrática de Apipucos, nas cercanias de Recife, do que a trajetória intelectual de seu próprio mestre.

Não esperemos, obviamente, um Itinerário, uma autobiografia semelhante do autor de Essas malditas mulheres, A faca no coração, o grande deflorador, Lincha tarado, Desastres do amor, Meu querido assassino, Pico na veia, Capitu sou eu, Macho não ganha flor, O maníaco do olho verde, Dinorá e Desgracida, entre muitos outros títulos, assemelhados e, no entanto, sempre diferentes de Dalton Trevisan: tal itinerário está inscrito a sangue, riso e lágrimas em sua própria literatura "minimalista". Algo que Joaquim Pedro de Andrade capturou com precisão em seu mencionado "namoro crítico" com a pornochanchada (o grande filão do mercado cinematográfico dos anos setenta, liberado e estimulado pela ditadura militar entre os cidadãos brasileiros adultos), que renderia seus dois filmes deliberadamente escandalosos, ou seja, à sua maneira infernais, impiedosos e sem concessões. Filmes que a literatura de Mário de Andrade, Oswald de Andrade, Manuel Bandeira e Carlos Drummond de Andrade (ver a versão cinematográfica do poema "O padre e a moça", 1965) permitiu, em boa parte, realizar, sendo Joaquim Pedro, sem dúvida, o maior leitor da literatura brasileira entre os cineastas do país. 
Feios, sujos E MALVAdos

A sujeira urbana de 0 poeta do Castelo reaparece em Guerra conjugal em pátios sórdidos e em casas despencadas. Mas, no longa-metragem, o "baixo" está em todos os lugares e não apenas nas ruas e nos sonhos do poeta. O "falar cafajeste" é a norma dos diálogos encenados em décors ora limpos ora sujos, conforme uma gradação social que varia entre faixas mais ou menos remediadas da classe média, habitante da periferia das grandes cidades $^{6}$. Essa estética da pobreza também tem, como se sabe, gradações de tom. Assim, se no apolíneo Bandeira, há um ar de beleza transcendente no âmbito de um bordel - e o que é Pasárgada senão um belo e aristocrático bordel situado nas nuvens? -, no dionisíaco Trevisan o leitor salta direto para o rés do chão e o âmbito do feio, do mau gosto e do grotesco. Atravessado por um humor que igualmente varia entre o cômico e o bizarro ou o sinistro, a linguagem cafajeste em seus contos não contempla nenhuma perspectiva que não a da derrota ou do desastre. Todos os sorrisos são, como se diz, amarelos e todos os choros quiçá dourados, mas da cor do ouro dos dentes postiços e das bijuterias, dos artefatos baratos que são cópias, simulacros do modelo proposto pelos meios de massa mais populares (WALDMAN, 1983, p. 203).

Nesse aspecto, percebe-se um traço datado na produção de estórias da primeira fase do autor - exatamente a que Joaquim Pedro explora - uma vez que os diálogos típicos das radionovelas e fotonovelas aí presentes são produtos que tiveram audiência apenas em meados do século XX. No entanto, ao contrário do que normalmente ocorre, o fato de remeter a um período específico da história não representa um problema, já que o modo como essa linguagem é trabalhada resulta sempre insólito e impiedoso. Por outro lado, Trevisan também foi, pouco a pouco, afinando a sua "lira maldizente" de acordo com os novos tempos; além de reescrever seus contos a ponto de suprimir verbos e mesmo mudar o tempo verbal, os modelos a serem copiados vão-se modificando, conforme as circunstâncias. O "Cemitério de elefantes" - título do segundo livro e do conto em que os "elefantes" são um bando de bêbados e o cemitério, um baldio ao lado do mercado da cidade (TREVISAN, 1964) - passa a aceitar novos "animais" nas ruas, a exemplo da jovem mendiga dependente de crack no segundo fragmento de Pico na veia, com seu linguajar característico, à revelia das normas gramaticais:

6 Ampliando esse espectro populacional, o escritor Cristóvão Tezza, em bela resenha de Pico na veia, escreve: "ricos ou pobres, tudo é povinho" (TEZZA, 2002). 
- O meu café da manhã é uma pedra. Se estou na pior, um baseado. Aí me dá uma fominha desgracida. Vou chegando bem doidona: "Ei, tô com fome. Ei, galera, tô com fome." Até descolar um rango. [...] Só fumo sozinha. Todo mundo é muito sozinho. Pô, tem vez que fumo com o negão, no mocozinho. Daí a gente dormimo junto. Fatal. (TREVISAN, 2002, p. 6 e 8).

O que também não quer dizer que o velho e bom cafajeste tenha desaparecido de sua literatura mais recente, quando sua produção se mantém alta, talvez até mais acelerada, com ao menos lançamento por ano. 0 vampiro-cafajeste, segundo Berta Waldman, "é a personagem que está a milhas de distância de seus modelos" e cuja linguagem é "ela mesma cópia". Trata-se dos bons e velhos clichês, "suporte que fixa a linguagem e a cristaliza como uma espécie de antilinguagem" (WALDMAN, 1983, p. 202), que se leem em seus textos. Os mesmos clichês que se ouvem no filme de Joaquim Pedro de Andrade, que consegue o milagre de respeitar literalmente as histórias originais de Dalton Trevisan no cinema, sem soar esquemático ou mecânico. "Ao trazer para a literatura linguagens já elaboradas (jornal, revista, rádio, TV, etc.), linguagens elas próprias formas do oco e do vazio, o autor rompe o ilusionismo da representação" (WALDMAN, 1983, p. 202-203), do mesmo modo que o cineasta e o escritor, na parceria de Guerra conjugal, rompem com a previsibilidade de um gênero fílmico, a pornochanchada, frustrando e perturbando seus expectadores habituais, em nome de uma funda sondagem das relações humanas através do escárnio e do kitsch.

\section{REFERÊNCIAS}

ANDRADE, Joaquim Pedro de. O poeta filmado. Diário de Notícias, Rio de Janeiro, p. 44, 17 abr. 1965.

BANDEIRA, Manuel. A estrela da vida inteira. 20. ed. Rio de Janeiro: Nova Fronteira, 1993. . Itinerário de Pasárgada. In: Poesia completa e prosa. Rio de Janeiro: Nova Aguilar, 1986. . Filme documentário. Jornal do Brasil, Rio de Janeiro, p. 28, 15 nov. 1959.

FREYRE, Gilberto. O esnobe da riqueza. O Cruzeiro, Rio de Janeiro, p. 54, 12 mar. 1960.

TEZZA, Cristóvão. Pico na veia, de Dalton Trevisan. Folha de S. Paulo, Suplemento Mais!, São Paulo, p. 4, 11 nov. 2002.

TREVISAN, Dalton. Pico na veia. Rio de Janeiro: Record, 2002.

WALDMAN, Berta. Do vampiro ao cafajeste. Uma leitura da obra de Dalton Trevisan. São Paulo: Hucitec; Curitiba: Secretaria da Cultura e do Esporte do Governo do Estado do Paraná, 1982.

. Surpresas do gênio nessa incrível arte de se repetir. IstoÉ, São Paulo, p. 60, 4 jan. 1978. 
Wolff, J. Falar cafajeste. De Manuel Bandeira a Dalton Trevisan via Joaguim...

. Tiro à queima roupa. Novos Estudos CEBRAP, São Paulo, v. 77, p. 255-259, 2007.

. A medida do cafajeste. In: SCHWARZ, Roberto (Org.). Os pobres na literatura brasileira.

São Paulo: Brasiliense, 1983.

Submetido em 27/07/2010

Aceito em 05/10/2010 